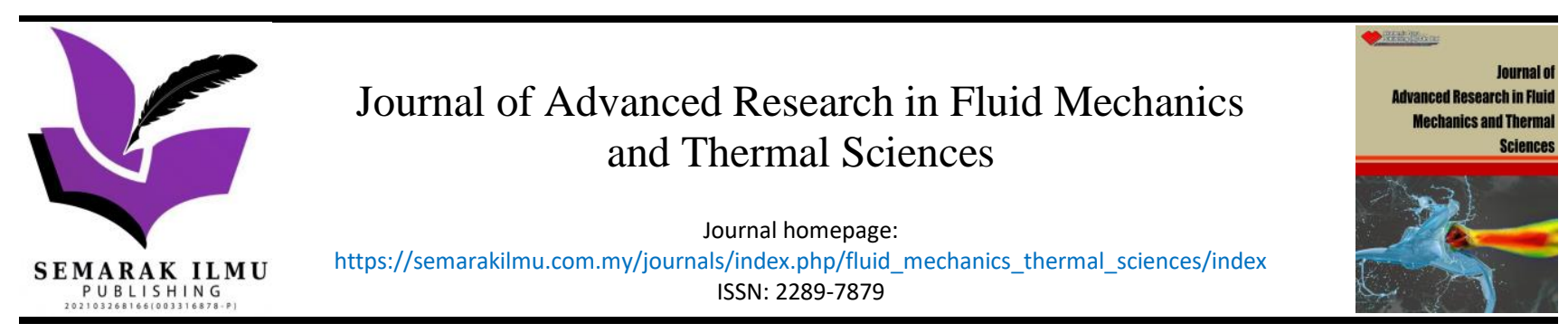

\title{
Vacuum Infusion Simulation for Radome Manufacturing Using Woven Flax Fibre and Glass Fibre
}

\author{
Mohd Yusoff Mohd Haris ${ }^{1,}{ }^{*}$, Khairul Dahri Mohd Aris ${ }^{1}$, Muzafar Zulkifli ${ }^{2}$, Tajul Adli Abdul Razak ${ }^{3}$, \\ Nurul Zuhairah Mahmud Zuhudi ${ }^{1}$ \\ Universiti Kuala Lumpur - Malaysian Institute of Aviation Technology, Lot 2891, 43800 Dengkil, Selangor, Malaysia \\ 2 Green Chemistry and Sustainable Research Cluster, Universiti Kuala Lumpur - Malaysian Institute of Chemical and Bio-Engineering Technology, \\ 78000 Alor Gajah, Melaka, Malaysia \\ 3 Universiti Kuala Lumpur - Malaysian Spanish Institute, Kulim Hi Tech Park, 09000 Kulim, Kedah, Malaysia
}

\section{ARTICLE INFO}

\section{Article history:}

Received 29 June 2021

Received in revised form 25 August 2021

Accepted 10 September 2021

Available online 7 November 2021

\section{Keywords:}

Permeability; Vacuum infusion; Mould design; Aircraft radome

\section{ABSTRACT}

\begin{abstract}
The vacuum infusion method is emerging to produce composite parts, especially thin wall structure aircraft radome. Ansys Fluent is used in the optimization phase for mould filling analysis on aircraft radome part. The permeability fibre is referring to the physical property of the fibre reinforcement to allow fluids to permeate it, thus it is correlated with the viscosity of the resin used. In this work, flax fibre, glass fibre and low viscosity epoxy resin are used to determine the permeability value of flax fibre, glass fibre and hybrid without using a flow medium. In-plane experiment on reinforcement fibre permeability is conducted and all reinforcement fibre have similar fibre architecture and weight. The development of a digital model from a top partial aircraft radome is obtained through a 3D scanner and CATIA. Ansys Fluent is used to optimize the location of the injection line and air vent for the epoxy. The Ansys Fluent analysis model is validated through the in-plane experiment filling time result for a flat model. Based on the simulation analysis, the location of the injection line is placed at the perimeter and the air vent at the centre. The filling time from the simulation for the flax fibre and hybrid fibre was estimated around 10 to 11 minutes. However, the filling time for glass fibre is approximate 2 hours which is longer than epoxy gel time. Furthermore, this method can be used in mould filing scenarios of thin wall structure within gel time of the resin.
\end{abstract}

\section{Introduction}

The vacuum infusion process is one of the out-of-autoclave technologies and it is a potential alternative to the autoclave for manufacturing composite structure components [1]. Vacuum infusion offers an alternative to an existing process by combining low investment in material and equipment compare to the autoclave process [1]. The infusion method is based on the principle of a pressure difference between the resin supply and the vacuum bag or cavity [2]. One of the significant parameters in the vacuum infusion process is permeability fibre. The permeability fibre is referring

\footnotetext{
* Corresponding author.

E-mail address: mohdyusoff@unikl.edu.my
}

https://doi.org/10.37934/arfmts.88.3.4956 
to the physical property of the fibre reinforcement to allow fluids to permeate it, thus it is correlated with the viscosity of the resin used. The equation governed in this process is based on Darcy's Law as shown in Eq. (1) with an assumption that Newtonian fluids are traveling at low velocity through a porous medium [1]. Where $Q$ is a volumetric flow $\left(\mathrm{m}^{3} / \mathrm{s}\right), \mathrm{K}$ is a permeability $\left(\mathrm{m}^{2}\right), A$ is cross section $\left(\mathrm{m}^{2}\right), \Delta \mathrm{P}$ is fall of the pressure, $\mu$ is viscosity resin (Pa.s) and $\mathrm{L}$ is a covered length $(\mathrm{m})$. In this work, an assumption of $\mathrm{K} 1$ equal to $\mathrm{K} 2$ has been made, while $\mathrm{K} 3$ is neglected due to thin layer.

$Q=\frac{K A \Delta \mathrm{P}}{\mu L}$

There are two experimental methods to determine permeability value, which are linear flow and radial flow experiments. Linear flow experiments are conducted by monitoring a linear flow front as it travels through a rectangular sample of the reinforcement material from one side to the other side. While radial flow experiments trace an elliptical flow front in two dimensions where the injection gate is at the centre $[1,3]$. The reinforcement permeability value is depending on the type of fibre and the viscosity resin used for the product. Natural fibre has high permeability when compared to glass fibre due to its hydrophilic property [4-6].

An aircraft radome is a structure encapsulating the antenna and protects the antenna from aerodynamic load and physical environment. A low speed aircraft radome normally has a wall thin structure and is made from glass fibre [7]. Natural fibre such as flax fibre and kenaf fibre has gained popularity due to an increasing requirement for developing sustainable materials for a new product $[4,5]$. Flax fibres are cost-effective and offer specific mechanical properties comparable to those of glass fibres [4, 6]. Haris et al., [8] have performed a comparison study between vacuum infusion and vacuum bagging methods. Both methods give a good comparable thickness consistency. Haris et al., [9] have conducted preliminary works on the minimum number of layers for aircraft radome application. Nevertheless, flow analysis and simulation in mould design will ensure the resin is impregnated at all surface areas.

Ansys fluent is a computational fluid dynamic software that is commonly used to simulate resin transfer mould and vacuum infusion process [10]. Vacuum infusion simulation can be done in 2D model [11-13] and 3D model $[10,14,15]$. Nowadays, a modern effort is used to simulate the vacuum infusion manufacturing process to address the reliability and repeatability concerns cost-effectively. In the present work, three-dimensional simulation of aircraft radome panel undergoes vacuum infusion process by using Ansys fluent. The permeability value for flax fibre, glass fibre and hybrid with epoxy resin is obtained through in-plane linear flow experiment. Then, followed by verification and validation of the computational model used for the flat panel by using Ansys fluent.

\section{Materials and Experiment Setup}

The permeability analysis is carried out by using flax fibre and glass fibre. Both fibres are woven twill $2 / 2$ weave pattern and $200 \mathrm{~g} / \mathrm{m} 2$. The density of flax fibre and glass fibres are $1500 \mathrm{~kg} / \mathrm{m} 3$ and $2500 \mathrm{~kg} / \mathrm{m} 3$, respectively as shown in Figure 1 . The resin used is a low viscosity epoxy resin PRIME ${ }^{\mathrm{TM}}$ 20LV with a slow hardener from GURIT. The pot life for this epoxy resin is one hour. 


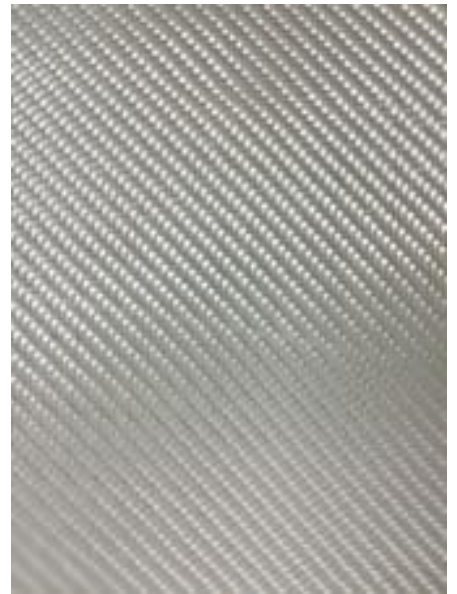

(a) Glass fibre

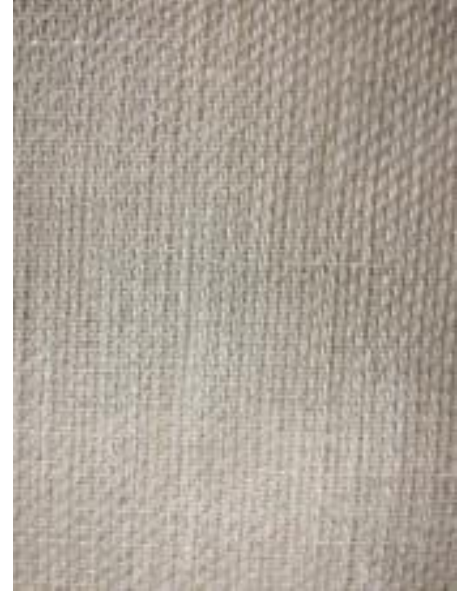

(b) Flax fibre

Fig. 1. The Fibre material twill 2 by 2 pattern, $200 \mathrm{~g} / \mathrm{m}^{2}$

Three samples were subjected to flow rate study which are flax fibre, glass fibre and hybrid flax/glass composite. Each composite sample was prepared for three sets and consist of six layers with $\left[0^{\circ}, 90^{\circ}\right]_{6}$ stacking sequences for the flat sample. The dimension for each layer is $125 \mathrm{~mm} \times 300$ $\mathrm{mm}$ the stacking sequence is shown in Figure 2. The experimental for linear flow vacuum infusion setup is shown in Figure 3. The work was started by stacking all the layers of woven fabric and covered by vacuum tight film. The vacuum was connected to impregnate fibre with epoxy resin. The duration of filling time was recorded throughout the process. The permeability value for each sample composite is calculated and to be used in flat panel model simulation using Ansys Fluent.

\begin{tabular}{|l|}
\hline Glass fibre \\
\hline Glass fibre \\
\hline Glass fibre \\
\hline Glass fibre \\
\hline Glass fibre \\
\hline Glass fibre \\
\hline
\end{tabular}

(a) Glass composite

\begin{tabular}{|l|}
\hline Flax fibre \\
\hline Flax fibre \\
\hline Flax fibre \\
\hline Flax fibre \\
\hline Flax fibre \\
\hline Flax fibre \\
\hline
\end{tabular}

(b) Flax composite

\begin{tabular}{|l|}
\hline Glass fibre \\
\hline Glass fibre \\
\hline Flax fibre \\
\hline Flax fibre \\
\hline Glass fibre \\
\hline Glass fibre \\
\hline
\end{tabular}

(c) Hybrid composite

Fig. 2. Woven fibre stacking sequence

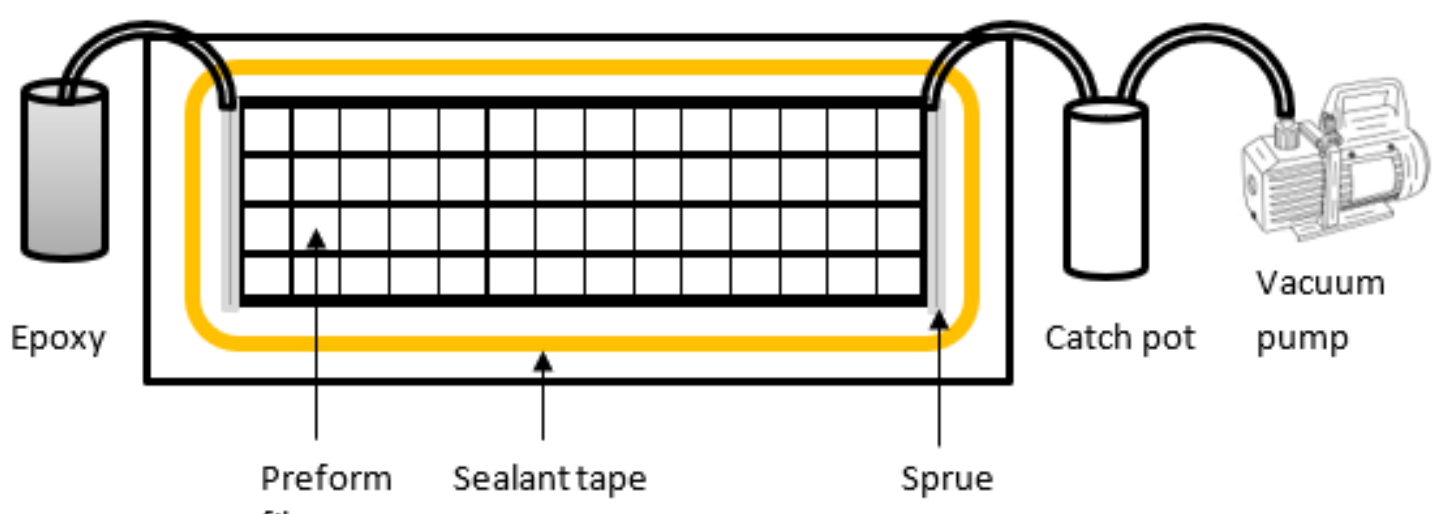

fibre

Fig. 3. Linear flow vacuum infusion setup 


\section{Development of Digital Radome Model}

An aircraft radome from Duke 60 Beechcraft was chosen as the radome model and the aircraft was located at UniKL MIAT hangar as shown in Figure 4. Normally, any aircraft design is confidential to the company. Therefore, the aircraft radome undergoes the reverse engineering design phase by using the 3D scanner for educational purposes. The partial aircraft radome component was refabricated and scanned using the Creaform GoScan50 3D scanner. Target is placed at the model before the scanning process as shown in Figure 5 to improve scanning data output result. The VXelement and the VXmodel software is used, respectively for scanning purpose and post-processing for a digital model of aircraft radome. Computer aided design software is needed to change the cloud of point data to a solid model.

The computer aided design software such as CATIA is used to create surface and solid model from the cloud of points generated from 3D scanning activity. The cloud of point data after the scanning process then was imported into the CATIA software. In the CATIA, the process begins with the development of a plane, section, wireframe, surface, and lastly to a solid model with thickness according to composite specimen thickness. The development process of the aircraft radome model was using CATIA V5 R19 is shown in Figure 6. Then, the solid model export to Ansys fluent for the computational fluid dynamic (CFD) analysis phase.

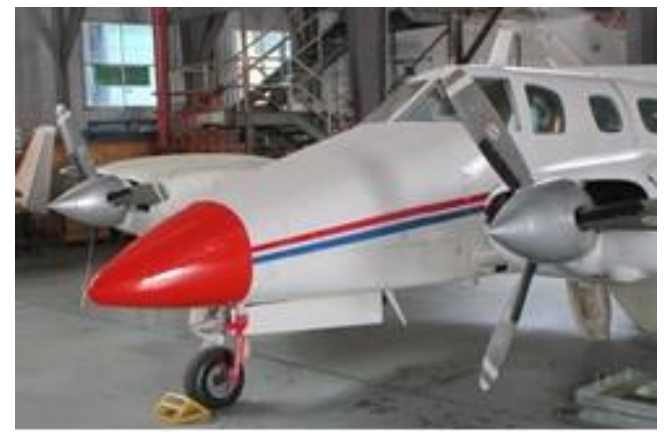

Fig. 4. Aircraft Duke 60 Beechcraft

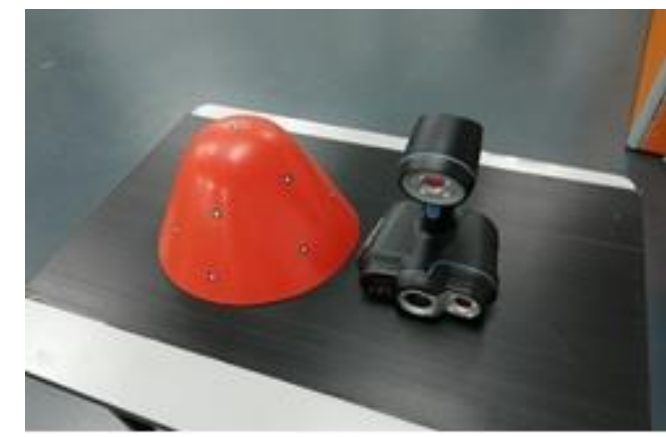

Fig. 5. Radome model and 3D scanner

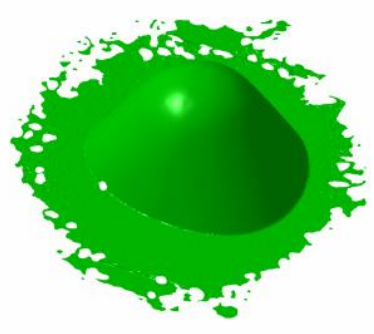

(a) Scanned data

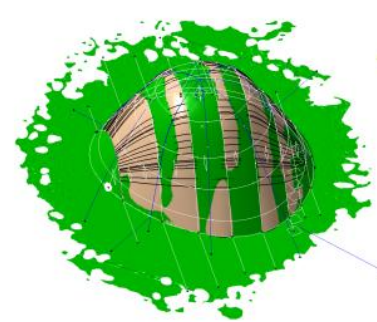

(d) Surface creation with multisurface

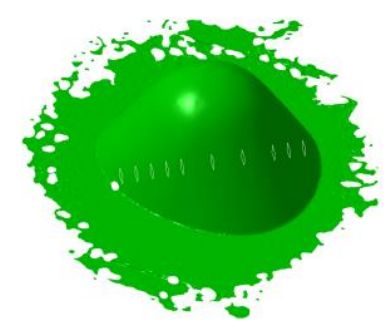

(b) Development of plane

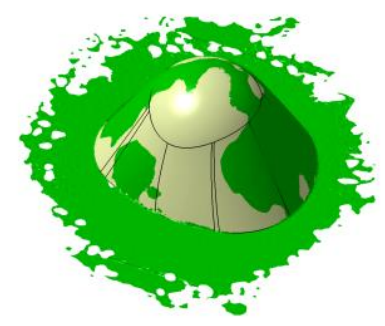

(f) Optimization surface

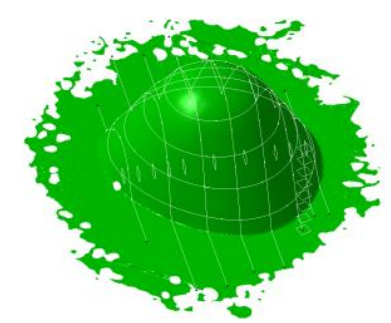

(c) Development of wireframe

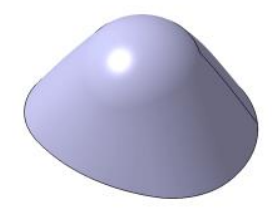

(g) Solid model

Fig. 6. Development model process using CATIA 


\section{Analysis using Ansys Fluent}

In this work, Ansys Fluent 17.2 was used to analyse filling time for flat and radome mould. There are three common phases for finite volume software which is pre-processor, solver, and postprocessor. For the pre-processor part, in the geometry section, the solid model was imported directly from the CATIA file having an extension file of .CATPart file. The pre-processing continues with a meshing stage, in which the optimized meshing was generated and the location of the injection line, air vent and wall were also determined in this stage. Then in the setup stage, all the required input parameters for analysis such as the values of resin density, viscosity, porosity, permeability, and pressure. Table 1 shows the epoxy resin properties. In the solver part, the solution methods are SIMPLE algorithm, PRESTO! and second order upwind [15-17] is selected. In the post-processing part, the filling time for the epoxy resin to fill up surface area was recorded and shown in Table 2.

Table 1

Epoxy resin properties [18]

\begin{tabular}{lll}
\hline & Density $\left(\mathrm{kg} / \mathrm{m}^{3}\right)$ & Viscosity at $25^{\circ} \mathrm{C}$ (Pa.s) \\
\hline PRIME $^{\text {TM }}$ 2OLV & 1.123 & 0.620 \\
Slow hardener & 0.936 & 0.016 \\
Mixture & 1.084 & 0.220 \\
\hline
\end{tabular}

\section{Result and Discussion}

The in-plane linear flow experiment is successfully carried out to determine permeability fibre via the vacuum infusion method. The fibre thickness and filling time is taken to determine volumetric flow, Q. Then the permeability value is calculated by using Darcy's law as shown in Eq. (1). The permeability result is shown in Table 2 . Then, the permeability fibre value is then used for simulation analysis on a flat mould to verify the finite volume model. The analysis filling time for flat mould was successfully done by using ANSYS Fluent software as shown in Figure 7. It can also observe that the filling time of the simulation was found to be as faster as compared to the filling time of the experiment results.

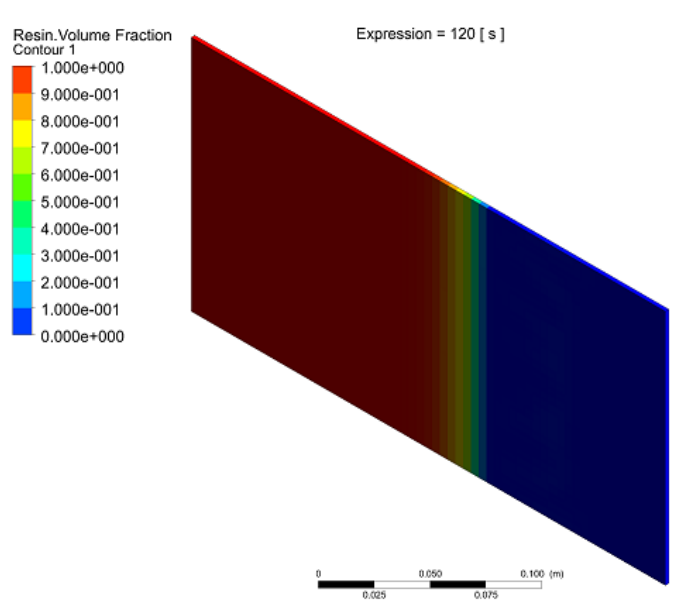

(a) time $=120$ second

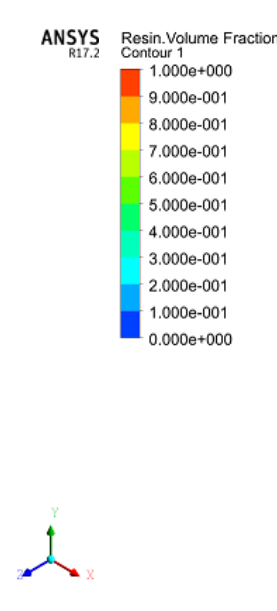

Fig. 7 .

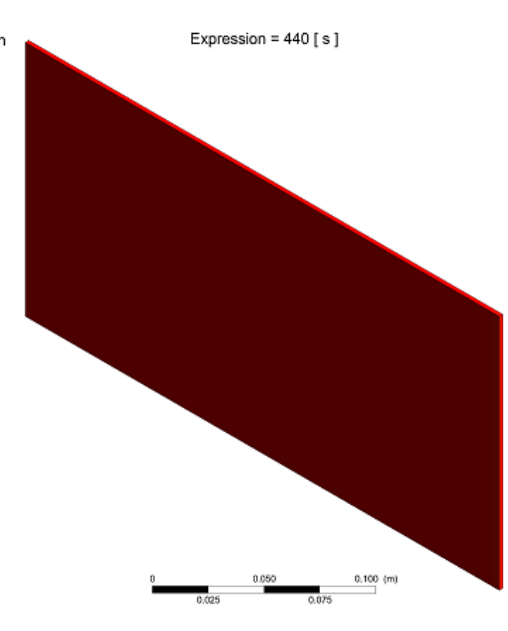

(b) time $=440$ second

$\underset{\text { R17.2 }}{\text { ANSYS }}$

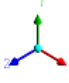

Fig. 7. Simulation of vacuum infusion on a flat mould with hybrid flax/glass fibre 
A similar model setup is used for simulating mould filling time for the radome part. The placement resin injection line is located at the perimeter and air vent at the centre of the aircraft radome part. Analysis filling time for radome mould was successfully done by using ANSYS Fluent software as shown in Figure 8. The filling time results from the simulation are shown below in Table 2.
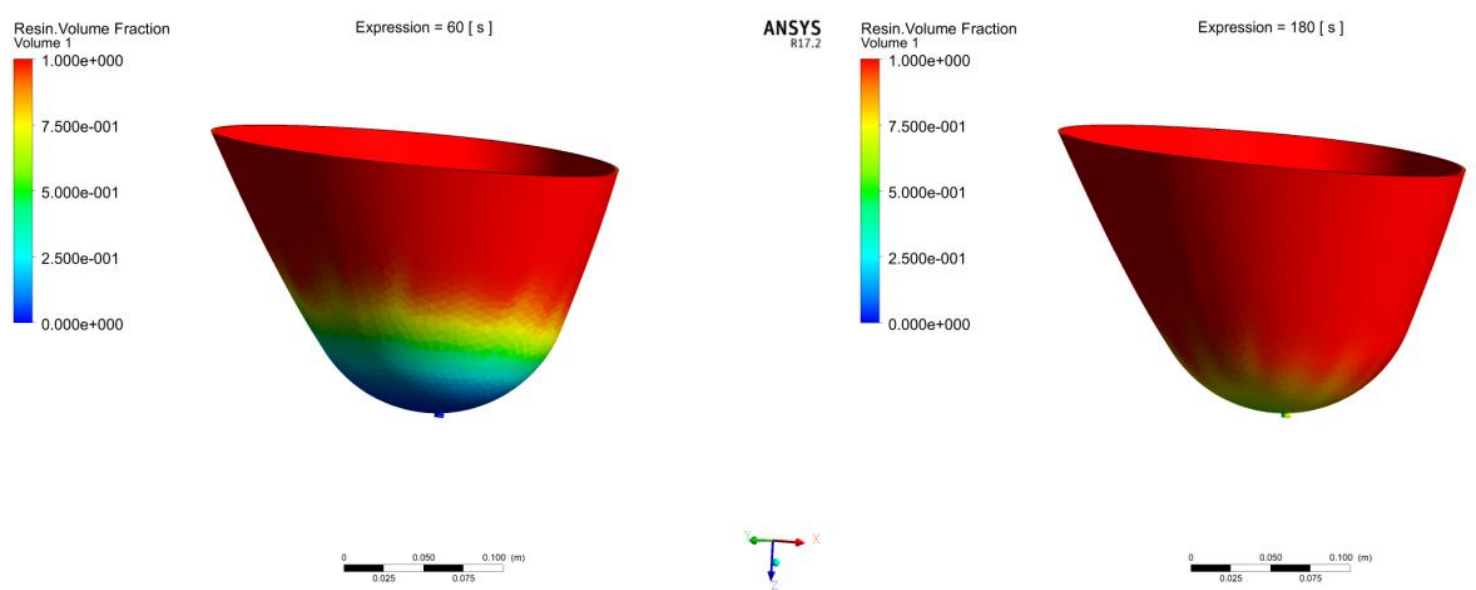

$\underset{\text { ANSYS }}{\text { R17.2 }}$

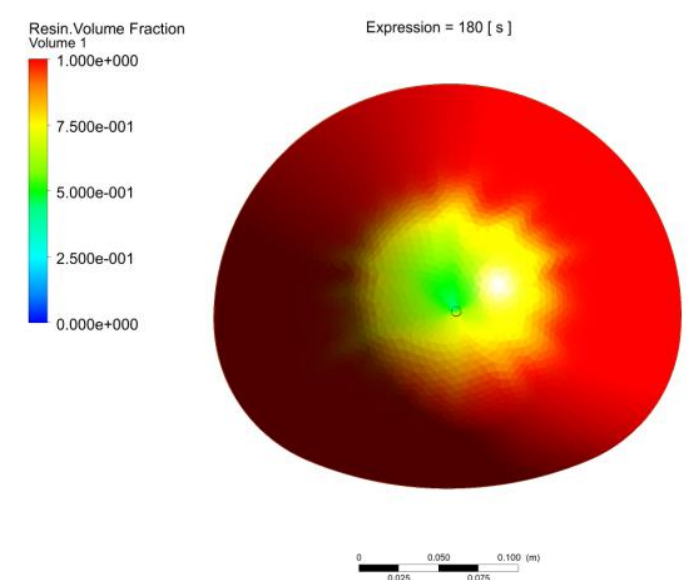

(a) time $=60$ second

(a) time $=180$ second
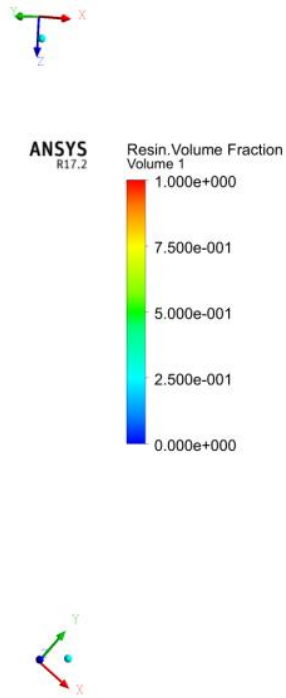

Fig. 8. simulation vacuum infusion on radome mould with hybrid flax/glass fibre (b) time $=180$ second

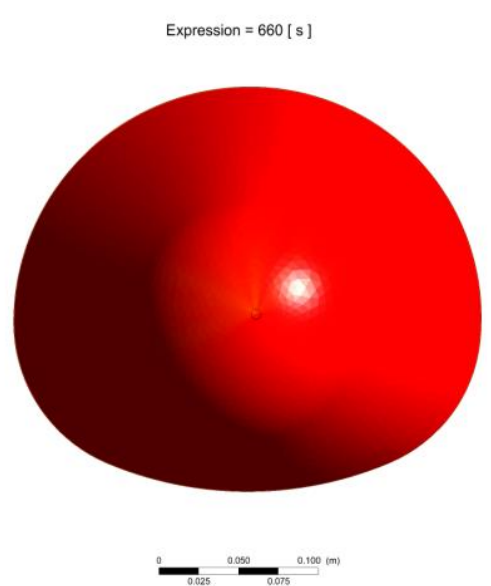

(b) time $=660$ second

Table 2

Experimental and simulation result

\begin{tabular}{llll}
\hline & Glass fibre & Flax fibre & Hybrid fibre \\
\hline Experiment filling time on flat mould $(\mathrm{sec})$ & 7214 & 471 & 486 \\
Permeability $\left(\mathrm{m}^{2}\right)$ & $2.892 \times 10^{-11}$ & $4.433 \times 10^{-10}$ & $4.274 \times 10^{-10}$ \\
Simulation filling time on flat mould $(\mathrm{sec})$ & 6750 & 420 & 440 \\
Simulation filling time on radome mould (sec) & 8800 & 600 & 660 \\
\hline
\end{tabular}

Interestingly, it can be observed that the filling time for the woven flax fibre composite exhibited the shortest time when compared to glass fibre composite due to the hydrophilic characteristic of natural fibre $[4,5]$. For hybrid laminate, it took a slightly longer time to fill up. Through the simulation analysis, fill up time is $9 \%$ to $10 \%$ faster compared to the experiment. For the filling time of the radome from simulation works, both flax and hybrid composite samples, showed only approximate 660 seconds or 11 minutes. However, glass fibre plies took more than two hours of filling time. Based on the technical data sheet provided by the supplier, the epoxy resin had already reached the limit of the pot lifetime. Assad and Farhan [19] suggest that multi size porous media is effect on the flow 
rate of liquid and in this work is fibre reinforcement diameter. It can conclude that the infusion process on glass fibre using radome mould is not recommended to be applied unless high permeability material is such as infusion mesh flow or medium flow for vacuum infusion to help expedite infusion filling time.

\section{Conclusion}

In this work, simulation vacuum infusion resin flow is conducted by using Ansys Fluent on six plies woven flax fibre, glass fibre and hybrid. An in-plane linear flow experiment is conducted to determine the epoxy resin flow rate under the vacuum infusion process. Then, the permeability constant for each sample is calculated by using Darcy's law. The in-plane linear simulation is conducted by using Ansys Fluent to validate that the filling time in the simulation is comparable with the experimental filling time. The good comparable results between the in-plane infusion experiment and simulation analysis indicate that shown Darcy's law is still valid for determining the permeability. And finally, simulation work on the aircraft radome model is successfully conducted by using a similar Ansys Fluent setup except for the type of meshing element. It can conclude that the work carried out for the experimental work and simulation work has been a good fundamental knowledge of the process before the actual fabrication process has been presented in this work.

The analysing work using computational fluid dynamics has an advantage in the conceptual design radome mould phase. A lot of what-if suitable location air vent design scenario is conducted before actual radome mould physically fabricate. Furthermore, filling time for the resin to impregnate all the surface area is within working duration or gel time resin. This comparison studies the filling time for the infusion process has been successfully carried out in this stage of research. It is suggested to further the simulation work about the modelling of radome mould and its filling time investigation with a validation work via experimental. The finding of this paper is significant to contribute to the gap of knowledge in this research area, especially in radome simulation processes.

\section{Acknowledgement}

This research was supported by Short Term Research Grant Universiti Kuala Lumpur (STRG17047 and STRG 17051)

\section{References}

[1] Chai, B. X., B. Eisenbart, M. Nikzad, B. Fox, A. Blythe, P. Blanchard, and J. Dahl. "Simulation-based optimisation for injection configuration design of liquid composite moulding processes: A review." Composites Part A: Applied Science and Manufacturing (2021): 106540. https://doi.org/10.1016/i.compositesa.2021.106540

[2] Hindersmann, Arne. "Confusion about infusion: An overview of infusion processes." Composites Part A: Applied Science and Manufacturing 126 (2019): 105583. https://doi.org/10.1016/i.compositesa.2019.105583

[3] Porto, Joseane da Silva, Max Letzow, Elizaldo Domingues dos Santos, Sandro Campos Amico, Jeferson Avila Souza, and Liércio André Isoldi. "Computational modeling of RTM and LRTM processes applied to complex geometries." Thermal Engineering 11, no. 1-2 (2012): 93-99. https://doi.org/10.5380/reterm.v11i1-2.62007

[4] Yan, Libo, Nawawi Chouw, and Krishnan Jayaraman. "Flax fibre and its composites-A review." Composites Part B: Engineering 56 (2014): 296-317. https://doi.org/10.1016/j.compositesb.2013.08.014

[5] Haris, M. Y., D. Laila, E. S. Zainudin, Faizal Mustapha, Rizal Zahari, and Zahurin Halim. "Preliminary review of biocomposites materials for aircraft radome application." Key Engineering Materials 471 (2011): 563-567. https://doi.org/10.4028/www.scientific.net/KEM.471-472.563

[6] Pil, Lut, Farida Bensadoun, Julie Pariset, and Ignaas Verpoest. "Why are designers fascinated by flax and hemp fibre composites?." Composites Part A: Applied Science and Manufacturing 83 (2016): $193-205$. https://doi.org/10.1016/i.compositesa.2015.11.004

[7] Kozakoff, Dennis J. "Analysis of radome-enclosed antennas." Artech House, 2010. 
[8] Haris, Mohd Yusoff, D. Laila, Amzari Zhahir, Faizal Mustapha, and K. D. Mohd Aris. "A comparative study of an aircraft radome closed mold through vacuum infusion technique." Advanced Materials Research 576 (2012): 690694. https://doi.org/10.4028/www.scientific.net/AMR.576.690

[9] Haris, M. Y., A. Fernandez-Lopez, KD Mohd Aris, Z. Muzafar, N. Z. M. Zuhudi, D. Laila, and K. Nurhafiza. "Preliminary analysis of hybrid laminate composite for aircraft radome application." IOP Conference Series: Materials Science and Engineering 697, no 1 (2019): 012032. IOP Publishing, 2019. https://doi.org/10.1088/1757899X/697/1/012032

[10] Isoldi, Liércio A., Cristiano P. Oliveira, Luiz AO Rocha, Jeferson A. Souza, and Sandro C. Amico. "Three-dimensional numerical modeling of RTM and LRTM processes." Journal of the brazilian society of mechanical sciences and engineering 34 (2012): 105-111. https://doi.org/10.1590/S1678-58782012000200001

[11] James Wang, T., Cheng-Hsien Wu, and L. James Lee. "In-plane permeability measurement and analysis in liquid composite molding." Polymer composites 15, no. 4 (1994): 278-288. https://doi.org/10.1002/pc.750150406

[12] Dong, Yin Fei, and Xue Jian Jiao. "The Simulation of RTM Based on FLUENT."Advanced Materials Researchvol 538 (2012): 873-876. https://doi.org/10.4028/www.scientific.net/AMR.538-541.873

[13] Yang, Bo, Tianguo Jin, Fengyang Bi, and Jianguang Li. "Modeling the resin flow and numerical simulation of the filling stage for vacuum-assisted resin infusion process." Journal of Reinforced Plastics and Composites 33, no. 21 (2014): 1976-1992. https://doi.org/10.1177/0731684414551039

[14] Masoodi, Reza, Krishna M. Pillai, Nick Grahl, and Hua Tan. "Numerical simulation of LCM mold-filling during the manufacture of natural fiber composites." Journal of Reinforced Plastics and Composites 31, no. 6 (2012): $363-378$. https://doi.org/10.1177/0731684412438629

[15] Hurtado Sánchez, Francisco José, Antonio Sánchez Kaiser, Antonio Viedma Robles, and Sebastián Díaz. "Numerical anlysis of the vacuum infusion process for laminated composites with different fiber orientations." Journal of Reinforced Plastics and Composites 34 (2015): 196-212. https://doi.org/10.1177/0731684414566361

[16] Earn, Lee Chern, Tey Wah Yen, and Tan Lit Ken. "The investigation on SIMPLE and SIMPLER algorithm through lid driven cavity." Journal of Advanced Research in Fluid Mechanics and Thermal Sciences 29, no. 1 (2017): 10-22.

[17] Tey, Wah Yen, Ryan Yuen Wye Hong, Yutaka Asako, Hooi Siang Kang, and Khai Ching Ng. "Analysis on computational efficiency of convection discretisation schemes in SIMPLE algorithm." Journal of Advanced Research in Fluid Mechanics and Thermal Sciences 58, no. 1 (2019): 100-117.

[18] Gurit Holdding AG PRIME ${ }^{\mathrm{TM}}$ 20LV - Epoxy Infusion System. 2015. Available from: https://www.gurit.com/Lmedia/Gurit/Datasheets/prime-20lv.pdf.

[19] Asaad Salim Bded and Farhan Lafta Rashid. "Effect of Multi Size Porous Media Properties on the Flow of Non-Darcy Regime." Journal of Advanced Research in Fluid Mechanics and Thermal Sciences 68, no. 1 (2020): 63-72. https://doi.org/10.37934/arfmts.68.1.6372 